\title{
MAKING GEOLOGY RELEVANT FOR INFRASTRUCTURE AND PLANNING
}

\author{
RL Terrington ${ }^{*}$, S Thorpe ${ }^{1}$, H Kessler $^{1}$, A Bidarmaghz $^{2}$, B Choudhary $^{2}$, M Yuan $^{2}$, S Bricker $^{1}$ \\ ${ }^{1}$ British Geological Survey/UKRI/Nottingham, United Kingdom \\ ${ }^{2}$ University of Cambridge, Cambridge, United Kingdom \\ *Corresponding author
}

\begin{abstract}
The urban population is projected to rise to $66 \%$ in 2050 to 7.6 billion. This has had, and will have, a profound effect on the geological and geomorphological character of the Earth's shallow geosphere. It is important to know the character and geometries of the geological deposits so that infrastructure is planned sensibly and sustainably, and urban areas can be reused responsibly to ensure that they help facilitate economic and social development. This brings major challenges for our cities, where there is increased pressure on resources, space and services. The geosciences have an important part to play in securing sustainable global cities - they can support urban innovation and city performance, reduce our environmental footprint and ensure greater resilience to natural hazards such as flooding and ground instability.
\end{abstract}

For more than 30 years the British Geological Survey has advanced the geoscientific understanding and 3D characterisation of urban environments, producing multi-themed spatial datasets for geohazards and ground investigation used across the environmental, planning and insurance sectors.

The BGS have collaborated with the University of Cambridge to better integrate geological data with landuse and infrastructure to look at the long-term impact on these types of activities at surface and subsurface. A 3D GeoLanduse layer was produced from the geological framework model of London. This vector-based grid means that many soil and rock properties (e.g. foundation conditions, groundwater levels, volume change potential), can be represented alongside landuse statistics and infrastructure type and correlated in the XYZ domain. Focus has been at geothermal potential of the ground surrounding residential basements and the broader correlation between geology, energy consumption and landuse at city scale using principle component analysis and cluster recognition.

\section{Introduction}

We have reached a key milestone in history where over half of the world's population now lives in urban areas. In 2014, it was estimated that $54 \%$ of the world's population lived in urban areas (up from $30 \%$ in 1954), and this is projected to rise to $66 \%$ in 2050 according to World Population Prospects (The 2014 Revision), when the urban population will grow by 2.5 billion people to a total of around 7.6 billion. This has had, and will have, a profound effect on the geological and geomorphological character of the Earth's shallow geosphere. It is important to know the character and geometries of the geological deposits so that infrastructure is planned sensibly and sustainably, and urban areas (including peri-urban and brownfield sites) can be reused responsibly to ensure that they help facilitate economic and social development.

This brings major challenges for our cities and surrounding resources where there is increased pressure on resources, space and services. The geosciences have an important, but often underappreciated part to play in securing sustainable global cities - they can support urban innovation and city performance, reduce our environmental footprint and ensure we are resilient to natural hazards such as flooding and ground instability.

For more than 30 years the BGS has advanced the geoscientific understanding and modelling of urban environments. The BGS have pioneered the scientific and technological development of 3D city-scale ground models (Campbell et al., 2010; Kessler et al., 2009; Lelliot, 2006; Royse, 2008) and our multi-themed spatial datasets for geohazards and difficult ground conditions are used across the environmental, planning and insurance sectors (Gakis, 2015; Kessler et al., 2015)

To unlock the economic potential of the ground in our cities and to demonstrate the value of the services it provides, from water, geothermal energy and building materials through to green infrastructure and human health, there is a need to develop an integrated 3D city geospatial model of both the above surface and below surface natural and artificial environment.

The need to identify and quantify the service benefits the ground can provide, the need for new forms of underground space management and an alignment of the many custodians of subsurface has recently been highlighted by the Government 
Office for Science Foresight Future of Cities Programme. To achieve this in practice, we need to demonstrate that we have the technological capability to link surface and subsurface city models and that by doing so we can i) improve the measurement of land value, ii) identify the most suitable land use(s), and iii) support the future of planning.

By combining emerging city modelling technologies and geospatial data analysis developed at the University of Cambridge (e.g. City Energy Models) with urban geological modelling (BGS) the appraisal of land viability in consideration of the whole city system above and below ground will be enabled. Such proof of concept is in keeping with new government directives for a low carbon economy, Digital Built Britain and increased productivity in the planning and construction sector.

In this study, two areas of differing size and detail were chosen to test the combination of city models/landuse with 3D geological data and associated properties. The broader area was constrained by the Greater London Authority boundary in the west and east, and by extent of the London and Thames Valley 3D geological model in the north and south. This area is approximately 1558 square $\mathrm{km}$. The smaller area was a focussed study in the Borough of Kensington and Chelsea which was 12.2 square $\mathrm{km}$.

In the wider Greater London Authority area, the aim was to join surface and subsurface geological data with landuse and statistical data such as population demographics and energy use generalised into the Lower Super Output Areas (LSOA) to appraise land viability both above and below ground for hazard identification and utilisation of geological resources. By combining these disparate but locally related datasets, patterns between these can be analysed to help make decisions on how best the surface and subsurface can be used.

For the borough of Kensington and Chelsea, the study focussed on looking at the long-term impact of residential basement structures on the surrounding ground temperatures using three different geological scenarios. These predictions will help local authorities understand the impact of underground structures on the subsurface, prevent the over-utilisation of this increasingly valuable resource, and manage planning of the subsurface better.

\section{3D geology - BGS}

\section{$2.13 D$ geological modelling at the $B G S$}

The BGS has a long history of constructing 3D geological framework models (i.e. stratigraphical surface models showing the base and top of geological units). Some of these models go back as far back as the early 1990s, such as the LOCUS project, which produced a series of 3D modelled surfaces of the geology of London such as the Base of the London Clay and Top of the Chalk (Ellison et al., 1993). This has partly been driven by increasing software and hardware capability (Kessler et al., 2009; Napier 2011), but also the digitisation of many key datasets such as geological maps (Smith, 2013), the scanning and digital transcription of boreholes into databases and standards such as AGS (https://www.ags.org.uk/), and increased availability of digital terrain models (DTMs) and topographical imagery (Giles et al., 2010). The standardisation of modelling procedures and practices (Ellison, 2002; Hatton et al., 2005; Riddick et al., 2008) and the enhancements to workflows to facilitate the construction and use of these models (Aldiss et al., 2012; Burke et al., 2015) has meant that $3 \mathrm{D}$ modelling is the primary tool for geoscience investigation by the BGS. 3D modelling underpins a broad range of research activities, and geological models are being developed at all scales from sites, to cities, to the UK landmass and continental shelf using a range of different software tools and methodological approaches. Increasingly, the shallow subsurface in cities (Kearsey et al, 2018; Price et al, 2010, 2007) has been the focus of $3 \mathrm{D}$ geological modelling at the BGS.

The London and Thames Valley 3D geological model (Burke et al., 2014) is the most prominent of these because of the plethora of major construction projects (e.g. HS2, Crossrail, Thames Tideway) and large population in the south east of England (Figure 1). The London Basin 1:50 000 resolution 3D geological model covers a total area of $4800 \mathrm{~km} 2$ in southeast England, from easting 450000 to 570000 and from northing 160000 to 200000 and extends to depth in excess of $150 \mathrm{~m}$. The model was constructed using the GSI3D software and technology (Kessler \& Mathers 2004, Kessler et al. 2009) into twelve $20 \times 20 \mathrm{~km}$ tiles, and merged after completion of the twelve tiles. Over 7000 boreholes were consulted in developing the 3D model, which helped to construct over 900 cross-sections which were the basis for the surface calculation for each of the units.

Figure 1 London and Thames Valley 3D geological model

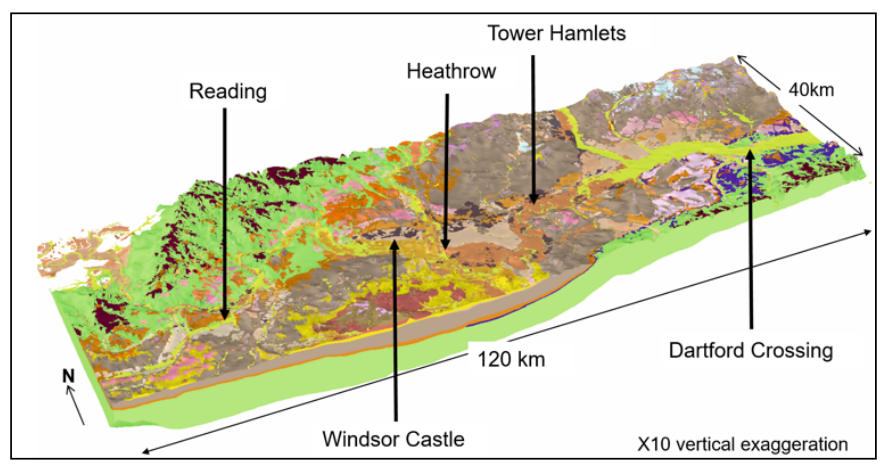

In total, 64 superficial and artificial geological units were modelled (including mass movement deposits). Using the BGS stratigraphic lexicon code (see https://www.bgs.ac.uk/lexicon/) and lithology. In addition 12 bedrock units have been defined in the cross-sections and their distributions (envelopes or coverages) mapped in GSI3D. These data were then exported to GOCAD ${ }^{\circ}$ for calculation of full faulted surfaces to complete the model.

The London and Thames Valley model outputs include the base, top and thickness of each of the geological units in a 
variety of formats including ASCII grids and TIN surfaces. Alongside this, the 2D geometrical surface and subsurface distribution were defined for each of the units and can be exported into vector or grid format. This model provided the basis for the 3D GeoLanduse layer onto which various properties were applied as it was the most extensive and detailed model that exists for the area of interest (section 3 ).

\subsection{Thematic maps and 3D models}

The BGS has created several thematic geological maps at a national scale, using the national superficial and bedrock maps in combination with engineering geology technical data and information. These thematic maps are available in two products - BGS Civils and BGS GeoSure.

BGS Civils is a suite of eleven engineering properties datasets. These comprise the following engineering geoproperty information:

- excavatability

- $\quad$ strength

- discontinuities

- bulking of soils and rocks

- $\quad$ sulfate and sulfide potential

- $\quad$ corrosivity (ferrous)

- $\quad$ use for fill

They demonstrate the spatial distribution of geological unit properties, primarily, for the uppermost $2 \mathrm{~m}$ across Great Britain. Within this limited depth, weathering of material is to be expected and, therefore, the effects of weathering are considered. The classifications are indicative of the characteristics expected. This might cover most of the range of the characteristics, or alternatively may describe the characteristics as minimum, typical and maximum expected values for each geological unit. The data are a synthesis of national databases and technical engineering data held by BGS, based primarily on DiGMapGB - 50 V6 and the National Geotechnical Properties Database (Entwisle et al., 2015). These engineering properties have informed the Foundation Conditions theme developed by BGS, a key influence when assessing landuse viability and future use.

The foundation conditions of rocks and soils are an important consideration for determining how surface construction loads are transmitted into the ground safely and for the lifespan of the project. The foundation is the interface of some form of construction and the ground. Design of the foundations takes into consideration several factors including the response of the ground to the stresses produced by the construction. The behaviour, or 'condition', of the ground may be assessed by in situ and/or laboratory tests during a typical site investigation. This dataset highlights common factors to consider when planning for a site investigation or land-suitability assessment. The main considerations are:

- $\quad$ strength or bearing capacity

- settlement (compressibility) and differential settlement

- volume change of the ground due to climatic conditions

- subsidence due to natural voids beneath the foundation, leading to ground failure

Other considerations include:

- weathering and alteration

- aggressive ground conditions of soluble sulfate, sulfide, low $\mathrm{pH}$ or high chloride content

- foundation excavations protection

The Foundation Conditions theme has been utilised in the Translucent Cities project with University of Cambridge for future land viability assessment, described in Section 4.

Alongside the BGS Civils layer is the BGS GeoSure thematic maps layer. BGS GeoSure is an insurance product that gives an index level assessment of the potential for a geological deposit to create financial insurance loss due to natural ground movement. These were produced as a series of digital maps, combining the types of geology at surface, with other information such as the geomorphological character of the land (slope and gradient) and water level in the slope. These maps show the most significant hazard areas across the UK that are associated with ground movement/subsidence (Lee and Diaz Doce, 2014). These include:

- $\quad$ landslides (slope instability)

- $\quad$ shrink-swell clays

- $\quad$ soluble rocks (dissolution)

- $\quad$ running sands

- compressible deposits

- collapsible deposits

The most relevant of these in London is shrink-swell clays because of the predominance of the London Clay Formation that underlies much of the Thames Basin area. The clay within the London Clay Formation is dominantly illite/smectite and is particularly susceptible to shrink-swell behaviour. It is highly plastic (Jones 2011). Swelling clays can change volume due to variation in moisture, this can cause ground movement, particularly in the upper two metres of the ground, or where excavated and exposed, which may affect many foundations. 
Ground moisture variations may be related to several factors, including weather variations, vegetation effects (particularly growth or removal of trees) and the activities of people that might cause changes to the ground conditions. Such changes can affect building foundations, and buried pipes or services.

The BGS have taken thousands of measurements on the London Clay Formation to determine the Volume Change Potential (VCP), which shows the extent to which the soil shrinks as it dries out or swells when it gets wet. Jones (2011) used several methods to portray the distribution at surface and in the subsurface using both Inverse Distance Weighting at several depths using 2D snapshots as rasterised GIS grids (e.g. Surface, $2 \mathrm{~m}$ below ground level, $5 \mathrm{~m}$ below ground level etc.). Voxel models have also been used for interpolation to show the $3 \mathrm{D}$ VCP across the London and Thames basin (Figure 2, shows a vertical slice through the voxel model) displaying the $3 \mathrm{D}$ pixels/cells which can be attributed with different properties.

Figure 2 Vertical slices through voxel model showing variability in shrink-swell VCP values

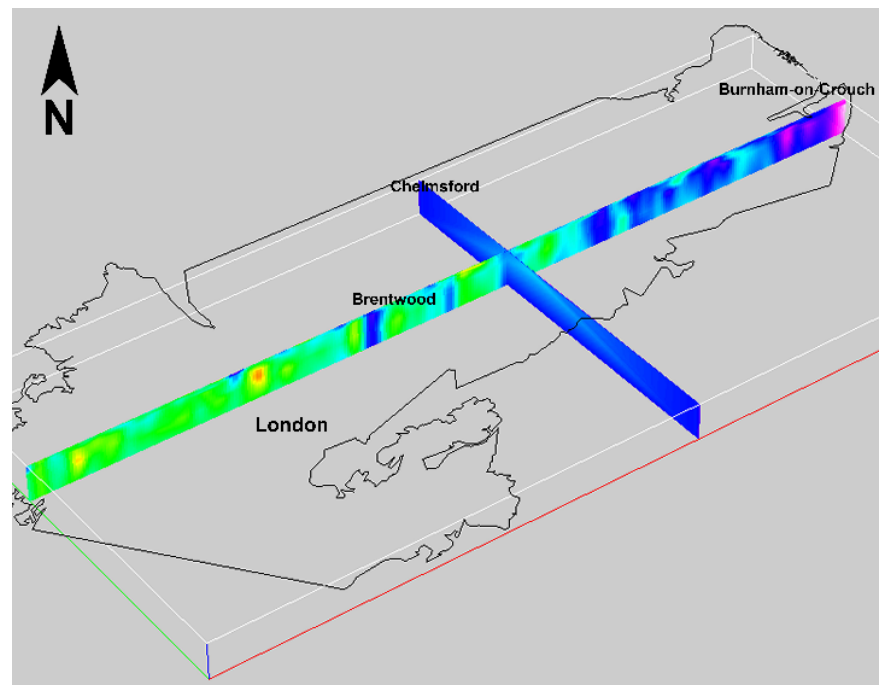

Although this gives a more realistic impression of the $3 \mathrm{D}$ distribution of VCP, these types of data are difficult to translate for geotechnical engineers and planners who typically use CAD and GIS software for their ground investigation. To improve the uptake of this type of data, the BGS produced a 3D Shrink-Swell layer in a GIS format - this is described in section 2.3 .

Alongside voxel/block modelling, the BGS has used bulk attribution on lithostratigraphical units to make these models more suitable for use by different industry sectors and relevant at depth beneath the subsurface. Both hydrogeological and geotechnical properties have been applied to 3D geological models with these attributes. Each of the lithostratigraphical units are attributed with a variety of information including strength, compressibility, permeability and porosity. The attributed geological model is now able to encapsulate, at least in part, some of the natural variability of real geological systems (Royse et al., 2009). A generic bulk description is applied to each unit regardless of depth, although descriptions attached to that unit may indicate if any of these attributes vary with depth (Figure 3).

Figure 3 Bulk attribution of 3D geological model with engineering properties

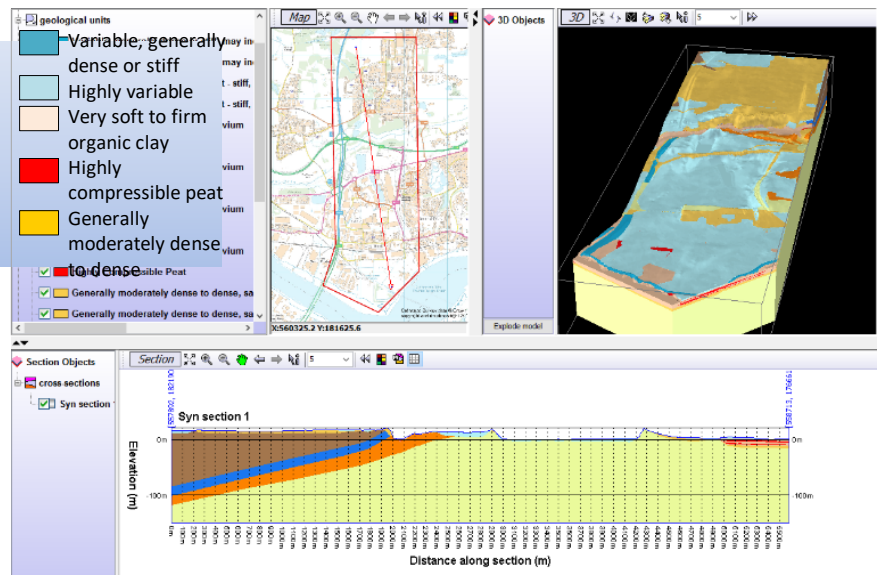

\subsection{D shrink swell}

The BGS have taken steps to make 3D data used more widely utilising Geographical Information Systems architecture for storing attributes within GIS vector data to create a pseudo 3D voxel/block model. This has been done on the shrink-swell clays data set utilising the framework provided by the London and Thames Valley Model. This has generated a regional hazard susceptibility map that identifies areas of potential shrink-swell hazard in three-dimensional space at intervals down to 20m (Jones and Hulbert, 2016).

The level of potential hazard does not mean that a damaging event is going to happen but is an indication of how many causative factors may be present and how severe they are thought to be. Thus, the hazard assessment method can be used to indicate how vulnerable areas are to experiencing hazard events and of how frequently these hazard events might be expected to occur.

Use of this data can help manage land to its best advantage, safely and with the lower likelihood of financial loss. Shrinkswell soils can have a damaging effect in tunnels and other underground spaces where specialist supports may be required; the 3D hazard map would help to identify areas for further investigation before construction begins.

The dataset is split into $50 \times 50 \mathrm{~m}$ grids and contains the following information per grid cell at intervals down to $20 \mathrm{~m}$ (0 m (surface geology), $1 \mathrm{~m}, 2 \mathrm{~m}, 3 \mathrm{~m}, 4 \mathrm{~m}, 5 \mathrm{~m}, 10 \mathrm{~m}, 15 \mathrm{~m}$, $20 \mathrm{~m}$.). This data layer provides information on the primary key 'Form' (Geological Formation), the secondary key 'VCP' (Dominant Volume Change Potential) and the tertiary key 'Range' (Volume Change Potential Range). In the Kensington and Chelsea borough the VCP changes quite significantly when comparing the geology at surface compared to $5 \mathrm{~m}$ below ground level (Figure 4). 
Figure $4 \mathrm{VCP}$ at surface and at $5 \mathrm{~m}$ below ground level (C) University of Cambridge)
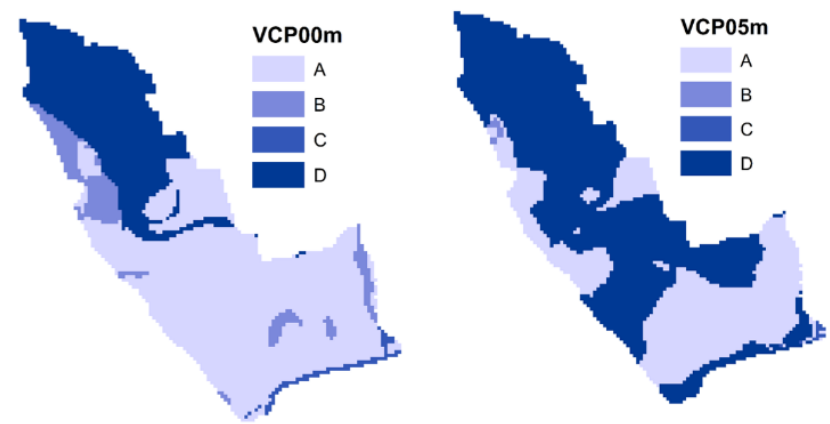

This dataset was then used as the framework to relate geological surface and subsurface conditions with infrastructure and demographic parameters such as energy use.

\section{3D GeoLanduse layer}

\subsection{Construction of the $3 D$ GeoLanduse layer}

The 3D GeoLanduse layer extends the 3D shrink-swell layer beyond the use of hazard susceptibility into a multi-variate, multi-dimensional landuse layer which can be used for planning, ground investigation and future subsurface utilisation. Alongside the shrink-swell VCP data, several other properties were attached such as foundation conditions and groundwater levels. All of these geoproperty data were joined using the LEX-RCS code already used in the shrink-swell layer, which describes the rock/soil type and dominant lithology. This data model displays the spatial variation of foundation conditions as three fields; foundation conditions, foundation hazards and additional foundation notes. Each has been assigned an alphanumeric class code linking each of these tables and then appended to the attribute table of the vector grid to allow easy visual comparison at different depths (Figure 5). Likewise, this has been done for the permeability indices dataset.

Figure 5 Foundation Conditions compared at surface and at $5 \mathrm{~m}$ below ground level (C) University of Cambridge)
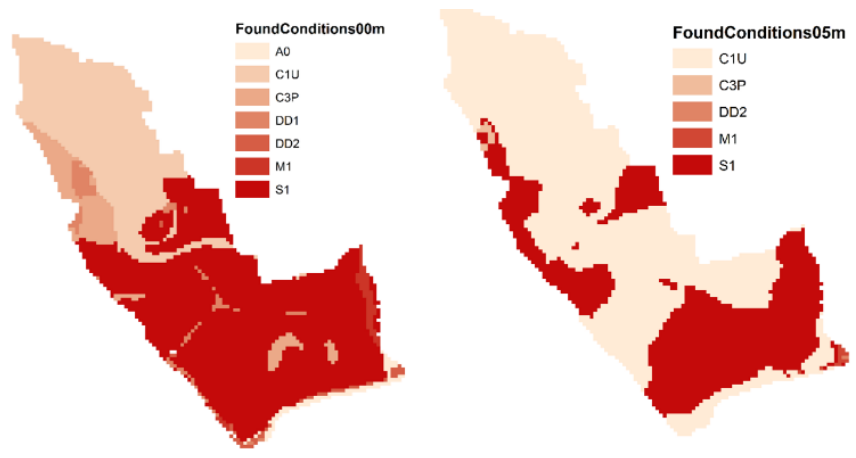

Other datasets have been applied directly as a numerical value such as the Digital Terrain Model elevation or the ground water level both relative to OD or depth below ground level.

\subsection{Application of 3D GeoLanduse layer}

The 3D GeoLanduse layer was applied in two separate studies by the University of Cambridge, the wider study in the Greater London Authority area and the other in a smaller area focussing on the Borough of Kensington and Chelsea. In the Greater London Authority area, the 3D GeoLanduse layer was subsumed into Lower Super Output Area (LSOA). The LSOA atlas provides a summary of demographic and related data for each LSOA areas in Greater London. The average population of an LSOA in London in 2010 was 1,722 compared with 8,346 for a Middle Super Output Area and 13,078 for a ward according to government statistics.

The profiles are designed to provide an overview of the population in these small areas by combining a range of data on the population, diversity, households, health, housing, crime, benefits, land use, deprivation, schools, and employment. By combining these with geological property data from the 3D GeoLanduse layer, geostatistical methods such as Principle Component Analysis can help visualise and analyse clusters of LSOA zones where the subsurface geology can be utilised, for example identifying areas of fuel poverty. In these areas, the subsurface geology can be assessed automatically for geothermal potential using the 3D GeoLanduse layer harnessing the value from the subsurface. Figure 6 shows clusters of similar landuse and building types used in this type of analysis. Differences in the built environment and energy attributes are found indicative for further analysis.

Figure 6 Cluster Analysis comparing landuse types (Contains public sector information licensed under the Open Government Licence v3.0, (C) University of Cambridge)

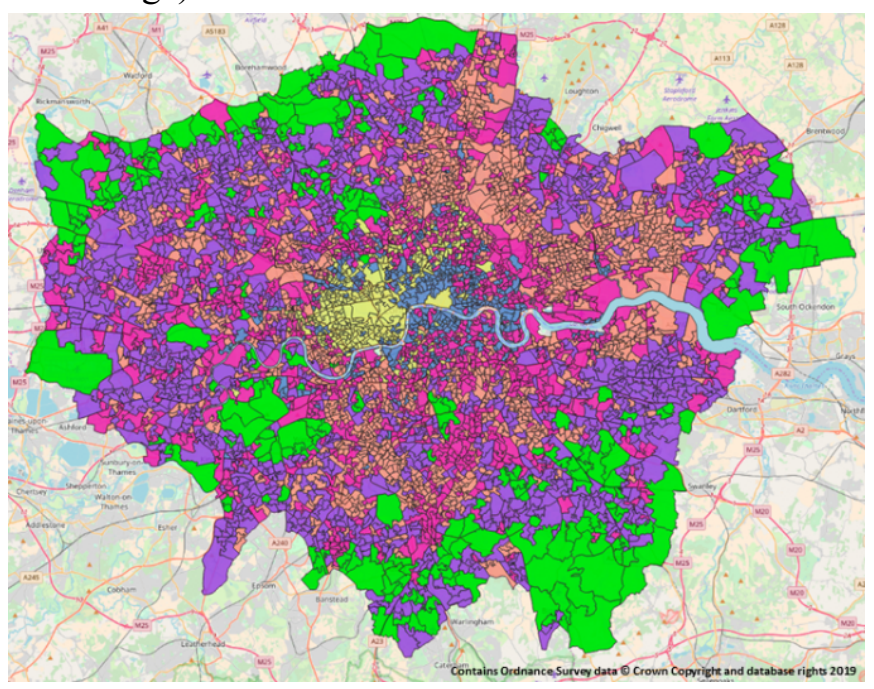

In the Borough of Kensington and Chelsea, the focus was on using the 3D GeoLanduse layer to identify the geothermal potential from the different rock types in the subsurface and the 
effect that basements could have in medium to long-term. The theory being that underground spaces influence local ground thermal state by heat dissipation in the subsurface. Complex finite element models of the subsurface were developed to quantify the city scale impact of underground spaces on longterm ground temperatures in three smaller areas of the Borough of Kensington and Chelsea that had different subsurface geological scenarios (Figure 7)

Figure 7 Case study areas for thermal interaction comparison between basements and the natural subsurface (C) University of Cambridge)

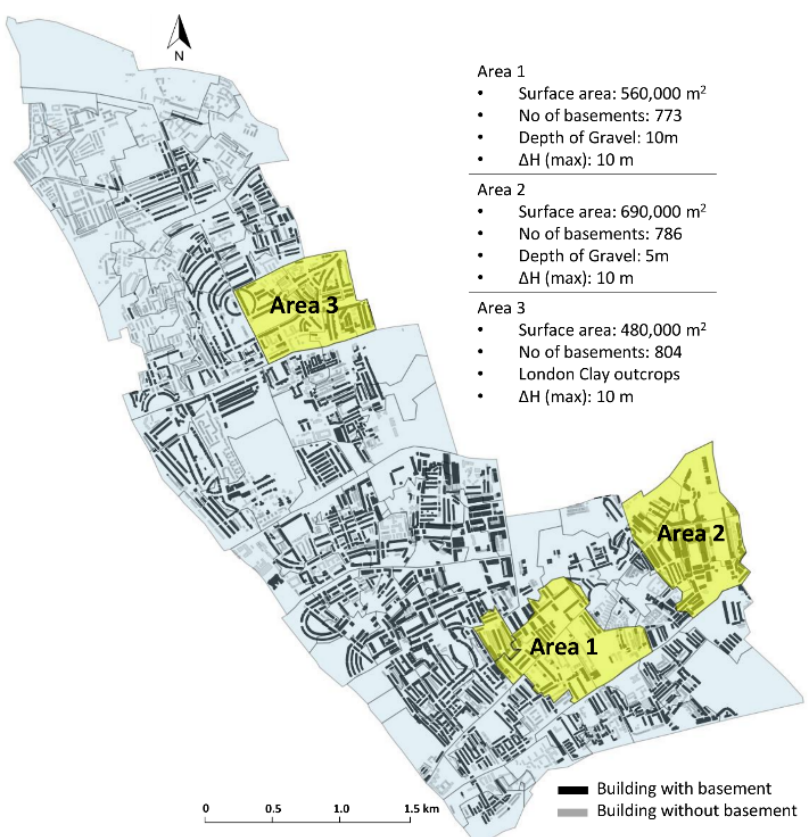

The key findings of the Kensington and Chelsea study were:

- Reliable knowledge of ground thermal status in urban areas is crucial for 1) sustainable development of underground structures, 2) optimal utilization of geothermal sources and 3) efficient energy system design for underground structures (Bidarmaghz et al., 2019).

- The amount of heat loss from underground structures, and the extent of thermal disturbance in the ground is dependent on the combination of geological and hydrogeological characteristics.

\section{Conclusion}

This study between the BGS and the University of Cambridge shows that it is possible to bring together disparate but physically linked data to harness the value of the subsurface for future planning and ground investigation. This will be increasingly important as urban space is pressurised and reduced to ensure that the potential value of the subsurface is not lost for future generations.

\section{Acknowledgements}

The BGS and University of Cambridge would like to thank InnovateUK for providing the funding for the Translucent Cities project.

\section{References}

Aldiss, D.T.; Black, M.G.; Entwisle, D.C.; Page, D.P.; Terrington, R.L.. 2012 Benefits of a 3D geological model for major tunnelling works : an example from Farringdon, eastcentral London, UK. Quarterly Journal of Engineering Geology and Hydrogeology, 45 (4). 405-414. https://doi.org/10.1144/qjegh2011-066

Bidarmaghz, A., Choudhary, R., Soga, K., Terrington, R. L., Kessler, H., Thorpe, S. 2019. A novel finite element approach for large-scale urban underground hydro-thermal modelling A case study of the Royal Borough of Kensington and Chelsea, London, Applied Energy (submitted)

Burke, H.; Mathers, S.J.; Williamson, J.P.; Thorpe, S.; Ford, J.; Terrington, R.L. 2014 The London Basin superficial and bedrock LithoFrame 50 Model. Nottingham, UK, British Geological Survey Open Report, 27pp. (OR/14/029)

Burke, H. F., Hughes, L., Wakefield, O. J. W., Entwisle, D. C., Waters, C. N., Myers, A., Thorpe, S., Terrington, R., Kessler, H., and Horabin, C. 2015. A 3D geological model for B90745 North Trans Pennine Electrification East between Leeds and York. Nottingham, UK, British Geological Survey Commercial Report, 28pp. (CR/15/004N)

Ellison, R A, Booth, S J, and Strange, P J. 1993. The British Geological Survey Locus Project: A Source Of High Quality Geological Maps And Computer Generated 3-D Models Of London Episodes, Vol. 16, 383-388.

Entwisle, D.; Lee, K.A.; Lawley, R.S.. 2015 User guide for 'BGS Civils': a suite of engineering properties datasets. Nottingham, UK, British Geological Survey Open Report, 28pp. (OR/15/065)

Giles, J.R.A.; Marsh, S.H.; Napier, B.. 2010 Dataset acquisition to support geoscience. In: Giles, J.R.A.; Marsh, S.H.; Napier, B., (eds.) Elevation models for geoscience. Geological Society of London, 135-143. (Geological Society Special Publications, 345).

Government Office for Science (2016) Future of Cities: The Science of Cities and Future Research Priorities, Foresight project - A report by the project's lead expert group. GS16/6.

Jones, L. Hulbert. A., 2016. User Guide for the Shrink-Swell 3D (GeoSure Extra) dataset v1.0. British Geological Survey Open Report OR/16/043.

Jones, L.D. and Terrington, R. (2011) Modelling Volume Change Potential in the London Clay. Quarterly Journal of Engineering Geology and Hydrogeology v. 44; p. 109-122

Kessler, H., Mathers, S., and H-G. Sobisch. 2009. The capture and dissemination of integrated 3D geospatial knowledge at the British Geological Survey using GSI3D software and methodology. Computers \& Geosciences. Vol. 35. p 13111321. 
Lee, K.A.; Diaz Doce, D., eds. 2014 User guide for the British Geological Survey GeoSure dataset. Nottingham, UK, British Geological Survey Open Report, 13pp. (OR/14/012)

Napier, Bruce. 2011 GeoVisionary : virtual fieldwork for real geologists. V1 Magazine.

Hatton, W.; Henley, S.; Napier, B.. 2005 Multi-dimensional modeling for BGS : the DGSM@2005 and beyond. In: Cheng, Q.; Bonham-Carter, G., (eds.) GIS and spatial analysis : proceedings of IAMG '05: the annual conference of the International Association for Mathematical Geology. York University, 255-260.

Price, Simon James; Terrington, Ricky Luke; Ford, Jonathan Richard; Crofts, Richard; Diamond, K.; Seymour, Keith. 2008 A 3D assessment of urban aquifer vulnerability using geological and buried asset models : a case study from Knowsley Industrial Park, NW England. In: European conference of the International Association for Engineering geology, Madrid, Spain, 15-20 Sept 2008.

Price, Simon J.; Burke, Helen F.; Terrington, Ricky L.; Reeves, Helen; Boon, David; Scheib, Andreas J.. 2010 The 3D characterisation of the zone of human interaction and the sustainable use of underground space in urban and peri-urban environments : case studies from the UK. Zeitschrift der Deutschen Gesellschaft fur Geowissenschaften, 161 (2). 219235. https://doi.org/10.1127/1860-1804/2010/0161-0219

Riddick, Andy; Laxton, John; Cave, Mark; Wood, Ben; Duffy, Tim; Bell, Patrick; Evans, Chris; Howard, Andy; Armstrong, Bob; Kirby, Gary; Monaghan, Alison; Ritchie, Calum; Jones, Dave; Napier, Bruce; Jones, Neil; Millward, David; Clarke, Stuart; Leslie, Graham; Mathers, Steve; Royse, Kate; Kessler, Holger; Newell, Andy; Dumpleton, Steve; Loudon, Vic; Aspden, John. 2005 Digital geoscience spatial model project final report. Keyworth, British Geological Survey, 56pp. (BGS Occasional Publication No. 9).

Royse, Katherine; Rutter, Helen; Entwisle, David. 2009 Property attribution of 3D geological models in the Thames Gateway, London : new ways of visualising geoscientific information. Bulletin of Engineering Geology and the Environment, 68 (1). 1-16. https://doi.org/10.1007/s10064008-0171-0

Smith, Alan. 2013 Digital Geological Map of Great Britain, information notes, 2013. Nottingham, UK, British Geological Survey Open Report, 54pp. (OR/13/007)

United Nations, Department of Economic and Social Affairs, Population Division (2015). World Urbanization Prospects: The 2014 Revision, (ST/ESA/SER.A/366). 